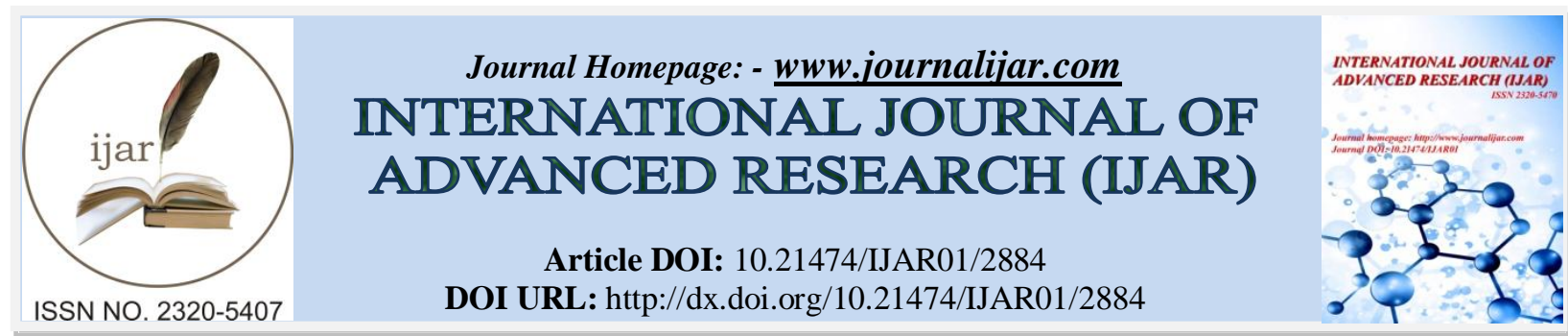

RESEARCH ARTICLE

\title{
KNOWLEDGE \& ATTITUDES TOWARD ELECTROCONVULSIVE THERAPY (ECT) AMONG A SAMPLE OF HEALTH FIELD STUDENT AND THE GENERAL PUBLIC IN SAUDI ARABIA AT "QASSIM"
}

Haifa Marzoog Alharbi , khawlah Ahmad Almansour, Fatima Mohammed al-olyan, Soad Abdulrhman Albshri , Bdoor saad alrasheedi and Farida khalaf alharbi.

\section{Manuscript Info}

Manuscript History

Received: 21 November 2016

Final Accepted: 21 December 2016

Published: January 2017

\section{Abstract}

Background :Electroconvulsive therapy (ECT) it is one of many methods used for treatment in hospital and ECT more we find them in the psychiatric clinic. However, the Electroconvulsive therapy has been demonstrated effective and safe treatment for a psychiatric disorder like depression, schizophrenia, and neuroleptic malignant syndrome, it has electrical polar which pass electrical through the brain when the patient under general anesthesia.

There are many stigmas is attached to the use of ECT, which undermines the acceptance of this treatment by the general public. In contrast to the negative view about ECT among the general public, studies, which have evaluated the knowledge and attitude of mentally ill patients who have received ECT and their relatives, suggest that they are mostly satisfied with the experience of ECT.

However, this is the first study focusing on awareness about ECT since there are no data on Qassim region about attitude or awareness of general public toward ECT.

Objective:

to explore the state of knowledge \& attitudes toward electroconvulsive therapy (ECT) among a sample of health field and the general public in Saudi Arabia at "Qassim".

Methods:By use the Cross- sectional study ... Extensive electronic was administered to health field student and the general public in Saudi Arabia at "Qassim" $(\mathrm{n}=200)$ to investigate the source of ideas about ECT, the extent of knowledge and attitude toward ECT.

Result:It is good to know that most of the health field student are well informed about ECT the score was about $64 \%$ compared to the general public about $36 \%$, the most age have the knowledge score is the age between 31-40 however the source of knowledge more from the internet $34 \%$ in compare to other sources. The health field student and the general public have a good attitude towards ECT (is an inhuman treatment) $61 \%$ of the sample disagreed with this statement. The health field student and the general public attitude towards ECT (is a painful treatment) $73.5 \%$ of the sample agreed with this statement. While attitude towards ECT (is that Need anesthesia) from the health field student and the general public $57.5 \%$ of the sample disagreed with this statement. In the view of the most cases improved by treatment. From 
the sample for the safety of ECT during pregnancy, show the health field student (29\%) and the general public (14\%) agreed to it implying that majority of the people did not consider ECT safe in pregnancy.

Keywords: Electro-convulsive therapy (ECT)

Copy Right, IJAR, 2016,. All rights reserved.

\section{Introduction:-}

Electroconvulsive therapy (ECT) involves the induction of a grand mal seizure through the passage of an electrical current to the patient's brain with the aim of improving the patient's mental status under anesthesia and muscle relaxant. There is no solid based clarification for the mechanism of action and how the ECT works but the most credibility goes to the biochemical theory. ECT is widely prescribed worldwide and first indicated in the emergency treatment of severe depression with suicide or psychosis, medication-resistant schizophrenia. ECT is also commonly used as an effective alternative to medication for patients who have a comorbid medical condition.

Modified and non-modified ECT are the two forms of the treatment, modification comes in the form of using anesthesia together with the muscle relaxant to limit the intensity of convulsion and reduce its side effects as bone and teeth fractures. Most of the internationally established guidelines recommended the modified ECT in the last decade as the standard routine treatment. Unilateral treatment is prescribed for some patients instead of bilateral to overcome the most frequently occurring side effects as temporary memory loss, mental confusion, and headache.

Despite controversies surrounding its use still remains one of the most efficacious treatment for the much severe mental disorder.

However, a lot of stigmas is attached to the use of ECT, which undermines the acceptance of this treatment by the general public. In contrast to the negative view about ECT among the general public, studies which have evaluated the knowledge and attitude of mentally ill patients who have received ECT and their relatives, suggest that they are mostly satisfied with the experience of ECT.

Studies which have evaluated the attitude of patients before and after ECT also show the attitudes become more positive after an experience of the treatment.

However, this is the first study focusing on awareness about ECT since there are no data on Qassim region about attitude or awareness of general public toward ECT.

Aim In this study, to examine the knowledge and attitude of the general public toward ECT.

\section{Objective:-}

to explore the state of knowledge \& attitudes toward electroconvulsive therapy (ECT) among a sample of health field student and the general public in Saudi Arabia at "Qassim".

\section{Methods:-}

Study Design: Cross- sectional descriptive study.

Study setting: this research done in Saudi Arabia at "Qassim".

Study Population: population less than 20, 20-30, 31-40 and more than 40.

\section{Data collection Technique:-}

Type of questionnaire:-

See the appendix

\section{sample size:-}

200(100 for health field in Saudi Arabia at "Qassim" and 100 for general population)

\section{Sample method:-}

A random sample will be collected from health field in Saudi Arabia at "Qassim" and the general public. 
The plane for data collection:-

The sample is divided into two groups, one for health field in Saudi Arabia at "Qassim" and another group for general public through electronic Questionnaires.

Table 1:- knowledge score in relation to study TYPE.

\begin{tabular}{|l|l|l|l|l|}
\hline \multirow{2}{*}{ College } & & Knowledge & Total \\
\cline { 3 - 5 } & & yes & no & \\
\hline \multirow{2}{*}{ health field student. } & Count & 64 & 36 & 100 \\
\cline { 2 - 5 } & $\%$ & $64 \%$ & $36 \%$ & $100 \%$ \\
\hline \multirow{2}{*}{ General public } & Count & 31 & 69 & 100 \\
\cline { 2 - 5 } & $\%$ & $31 \%$ & $69 \%$ & $100 \%$ \\
\hline \multirow{2}{*}{ Total } & Count & 95 & 105 & 200 \\
\cline { 2 - 5 } & $\%$ & 47.5 & $52.2 \%$ & $100 \%$ \\
\hline
\end{tabular}

The table show that significantly less knowledge more among general public: 36\%compared to64\%of health field student.

Table 2:- Description the relation between the age and the knowledge.

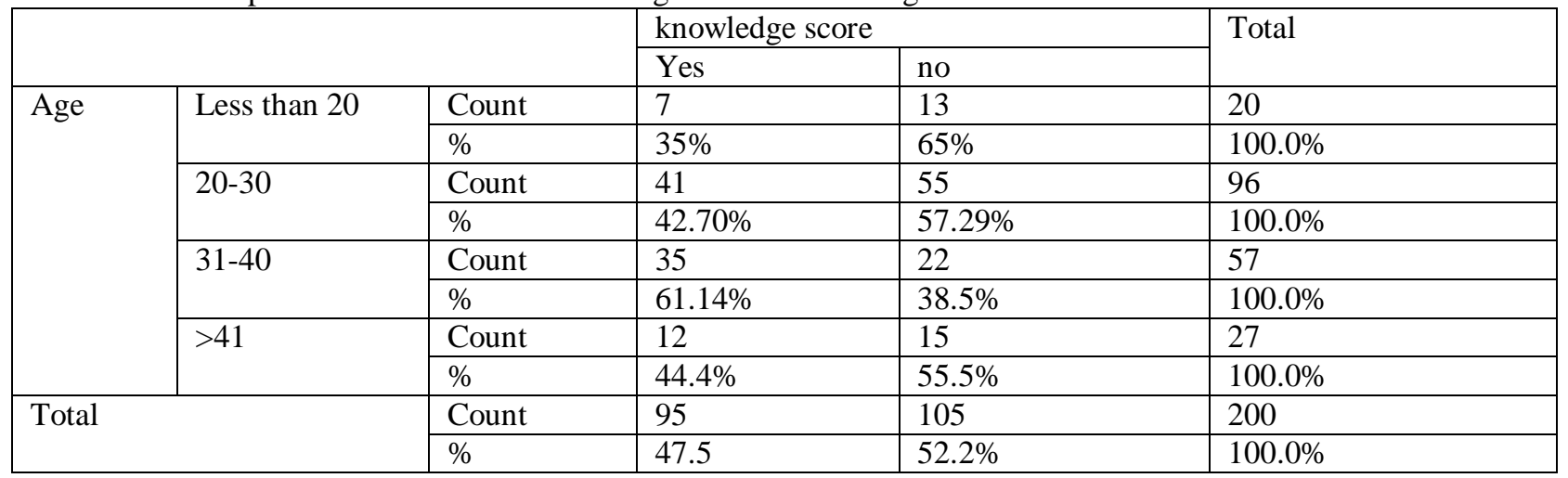

Table 3:- Illustrates the knowledge score related to sex.

\begin{tabular}{|l|l|l|l|l|}
\hline \multirow{2}{*}{ Sex } & & knowledge score & Total \\
\cline { 3 - 5 } & Mes & 54 & 58 & \\
& & $48.2 \%$ & $51.7 \%$ & 112 \\
\cline { 2 - 5 } & Female & 41 & 47 & 88 \\
\hline Total & $46.5 \%$ & $53.4 \%$ & 200 \\
\hline
\end{tabular}

Table 4:- The table shows the source of knowledge

\begin{tabular}{|c|c|c|c|c|c|c|c|}
\hline & \multicolumn{4}{|c|}{ Sources } & \multirow{2}{*}{ Total } \\
\hline & & & book & T.V & Internet & $\begin{array}{l}\text { Relative or } \\
\text { friend } \\
\text { experience }\end{array}$ & \\
\hline \multirow[t]{4}{*}{ Gender } & \multirow[t]{2}{*}{ male } & Count & 7 & 24 & 17 & 12 & 60 \\
\hline & & $\%$ & $11 \%$ & $40 \%$ & $28 \%$ & $20 \%$ & $100.0 \%$ \\
\hline & \multirow{2}{*}{ female } & Count & 11 & 11 & 24 & 12 & 60 \\
\hline & & $\%$ & $18 \%$ & $18 \%$ & $40 \%$ & $20 \%$ & $100.0 \%$ \\
\hline \multirow[t]{2}{*}{ Total } & & Count & 18 & 35 & 41 & 24 & 120 \\
\hline & & $\%$ & $15 \%$ & $29 \%$ & $34 \%$ & $20 \%$ & $100.0 \%$ \\
\hline
\end{tabular}

The table shows that they get the knowledge from internet $34 \%$ in compare to

T.V: $29 \%$, relativelfriend experience: $20 \%$ and book: $15 \%$ 
Table 5:- This table show the medical and non-medical attitude towards ECT (ECT is an inhuman TREATMENT).

\begin{tabular}{|c|c|c|c|c|}
\hline & & inhul & & Total \\
\hline & & yes & no & \\
\hline Medical & Count & 29 & 71 & 100 \\
\hline & $\%$ & $29 \%$ & $71 \%$ & $100.0 \%$ \\
\hline Non medical & Count & 49 & 51 & \\
\hline & $\%$ & $49 \%$ & $51 \%$ & $100.0 \%$ \\
\hline Total & Count & 78 & 122 & 100 \\
\hline & $\%$ & $39 \%$ & $61 \%$ & $100.0 \%$ \\
\hline
\end{tabular}

This table shows the medical and non-medical good attitude towards ECT $61 \%$ of the sample disagreed with this statement.

Table 6:- This table show the medical and non-medical attitude towards ECT.

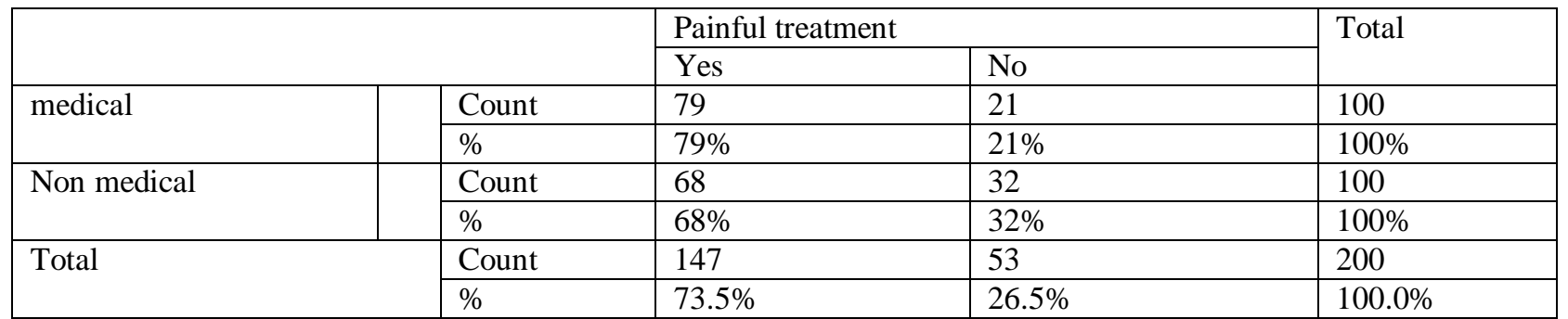

This table show the medical and non-medical attitude towards ECT 73.5\% of the sample agreed with this statement

Table 7:- This table show the medical and non-medical attitude towards ECT

\begin{tabular}{|c|c|c|c|c|}
\hline & & Need a & & Total \\
\hline & & yes & no & \\
\hline Medical & Count & 46 & 54 & 100 \\
\hline & $\%$ & $46 \%$ & $54 \%$ & $100.0 \%$ \\
\hline Non medical & Count & 39 & 61 & 100 \\
\hline & $\%$ & $39 \%$ & $61 \%$ & $100.0 \%$ \\
\hline Total & Count & 85 & 115 & 200 \\
\hline & $\%$ & $42.5 \%$ & $57.5 \%$ & $100.0 \%$ \\
\hline
\end{tabular}

This table show the medical and non-medical attitude towards ECT57.5\% of the sample disagreed with this statement.

Table 8:- This table show the knowledge of the duration OF ECT.

\begin{tabular}{|c|c|c|c|c|c|}
\hline & & & Duration & & Total \\
\hline & & & medical & Non medical & \\
\hline & One & Count & 26 & 21 & 47 \\
\hline & & $\%$ & $55 \%$ & $44 \%$ & $100.0 \%$ \\
\hline & $2-3$ times & Count & 25 & 15 & 40 \\
\hline & & $\%$ & $62 \%$ & $37 \%$ & $100.0 \%$ \\
\hline & Depend on the & Count & 49 & 65 & 114 \\
\hline & disorder & $\%$ & $42 \%$ & $57 \%$ & $100.0 \%$ \\
\hline Total & Count & & 100 & 100 & 200 \\
\hline & $\%$ & & $100 \%$ & $100 \%$ & $100.0 \%$ \\
\hline
\end{tabular}

Table 9:- This table show side effect.

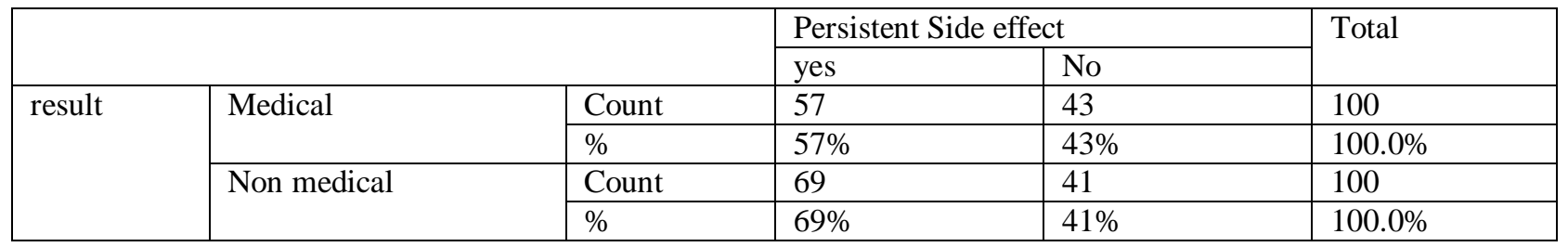




\begin{tabular}{|l|l|l|l|l|}
\hline \multirow{2}{*}{ Total } & Count & 126 & 74 & 200 \\
\cline { 2 - 5 } & $\%$ & $55.6 \%$ & $44.4 \%$ & $100.0 \%$ \\
\hline
\end{tabular}

The table show most cases improved by treatment.

Table 10:- Comparison between efficacy of ECT VS medical treatment.

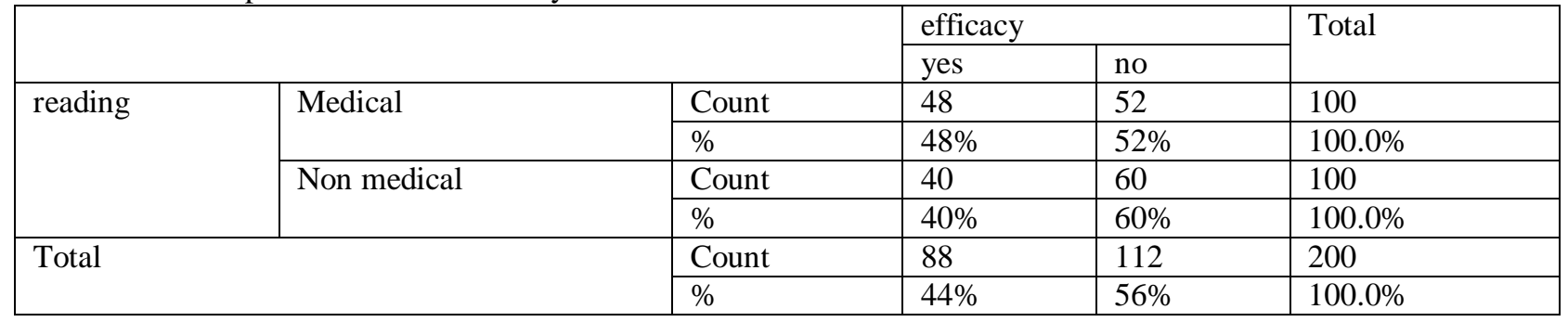

Table 11:- this table show the medical and non-medical attitude towards ECT

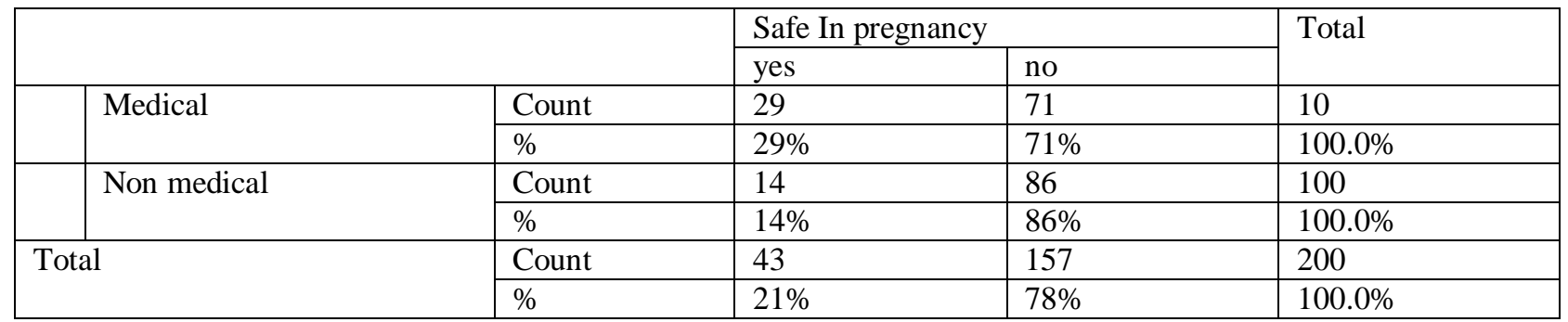

The table show only a few of the medical (29\%) and non-medical(14\%) agreed to it implying that majority of the people did not consider ECT safe in pregnancy.

\section{THE SOURCE OF KNOWLEDGE}

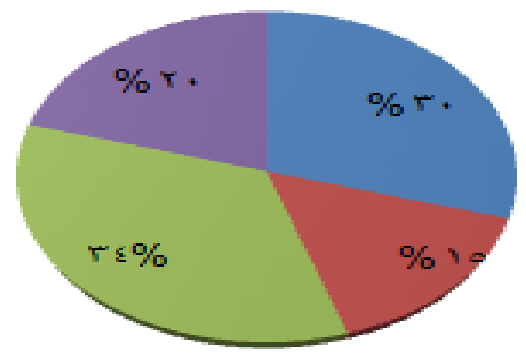

\section{The score of health filed student and the general publicattitude towards ECT ( ECT is an inhuman treatment).}

No

Yes

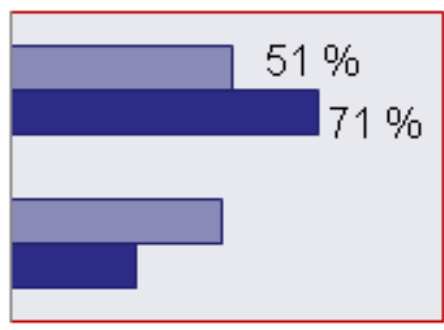

general public

- health filed student 


\section{Conclusion:-}

IT IS GOOD to know that most of the health field student are well informed about ECT , the score was about 64\% compared to the general public about $31 \%$, the most age have the knowledge score is the age between 31-40 .however the source of knowledge more from internet $34 \%$ the in compare to other sources . The health field student have a good attitude towards ECT (is an inhuman treatment) $71 \%$ of the sample disagreed with this statement. The health field student and the general public attitude towards ECT (is a painful treatment) $73.5 \%$ of the sample agreed with this statement. While attitude towards ECT (is that Need anesthesia) from the health field student and the general public 57.5\% of the sample disagreed with this statement. In the view of the most cases improved by treatment. From the sample for the safety of ECT during pregnancy, show the health field student $(29 \%)$ and the general public (14\%) agreed to it implying that majority of the people did not consider ECT safe in pregnancy.

\section{Recommendation:-}

we consider that there are many options in the treatment that it has a benefit as well as side effects, but should the person know both, so he can choose what is he would prefer to the treatment. And we LIKE TO clear about the ECT treatment that it gives us a positive result, not causes any pain under general anesthesia and safe for pregnant and this is what approved in the previous researchers.

The Appendix: - ....

\begin{tabular}{|l|l|ll|}
\hline 1) AGE... & 2) GENDER... & \multicolumn{2}{|l|}{ 3) EDUCATIONAL LEVEL } \\
\hline Below 20 & Male & - & Academic medical specialization \\
$20-30$ & Female & - & Academic non-medical specializati \\
$31-40$ & & - & Non- academic \\
Above 40 & & & \\
\hline
\end{tabular}

4) do you have information about electroconvulsive therapy sessions?

Yes / no

5) if yes, what are the sources of your information?

Book

Internet

Television

A relative or friend dealing with electroconvulsive therapy

6) do you think that the electrical therapy sessions method of treatment is inhumane?

Yes / no

7) do you think that electroconvulsive therapy sessions painful?

Yes / no

8) do you think that the fear and anxiety that accompanies attending the proceedings is the reason why many patients refused to use this type of treatment?

Yes / no

9) do you think that the electricity therapy sessions require anesthesia?

Yes / no

10) how many sessions needed by the patient to give the desired results?

One session

Two to three on average

Vary depending on the disease

11) do you think that therapy sessions lead to get used to it?

Yes / no

12) do you know someone who has this kind of treatment?

Yes / no

13) if yes, did he/she responded to treatment?

Yes / no

14) it does result in symptoms of long-term side effect?

Yes / no

15) do you think electroconvulsive therapy sessions safe for pregnant women?

Yes / no 
16) do you think the use of electroconvulsive therapy sessions more effective than drug?

Yes / no

17) do you think the electroconvulsive therapy session given to only hopeless cases?

Yes / no

18) do you think that modern scientific research proving effectiveness electroconvulsive therapy?

Yes / no

\section{References:-}

1. http://www.ncbi.nlm.nih.gov/pubmed/18648319

2. http://www.ncbi.nlm.nih.gov/pmc/articles/PMC2913640/\#!po=34.1667

3. http://www.sciedu.ca/journal/index.php/jnep/article/viewFile/2049/1442 